\title{
Notes on the vocalizations of Woodchat Shrike (Lanius senator)
}

Peter Boesman

In the following we briefly analyze and compare voice of the different races of Woodchat Shrike (Lanius senator). We also try to quantify the extent of any vocal differences using the criteria proposed by Tobias et al. (2010), as a support for taxonomic review. We have made use of sound recordings available on-line from Xeno Canto (XC).

Our main aim is to compare the morphologically quite distinct race badius vs. the other races.

We have only found three recordings of badius :

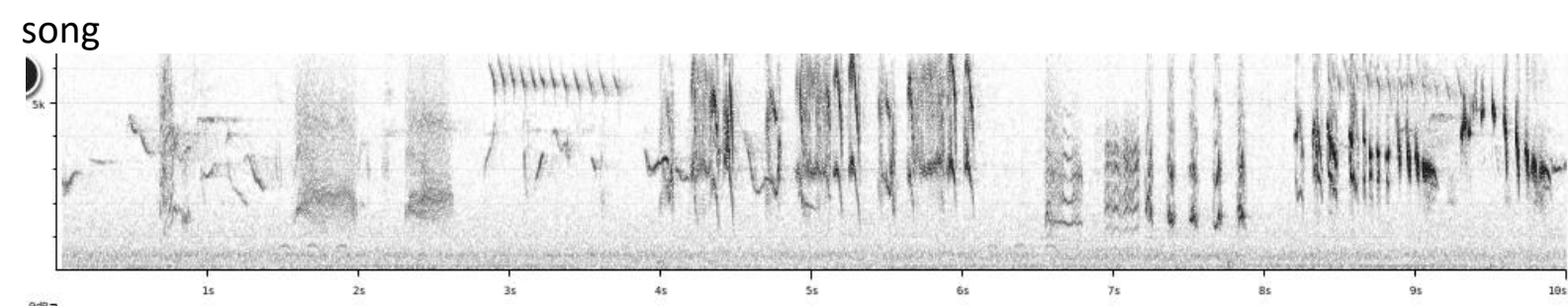

hoarse screechy calls (begging call ??)

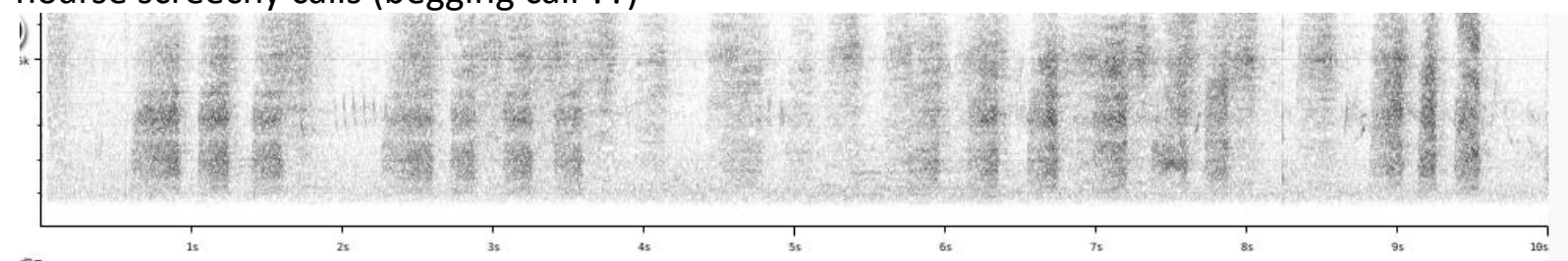

fast scratchy calls

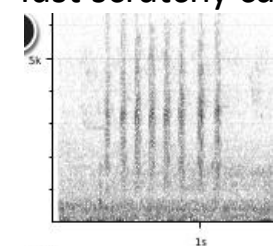

$\rightarrow$

I have looked for recordings from other races that come close to these vocalizations:

song:

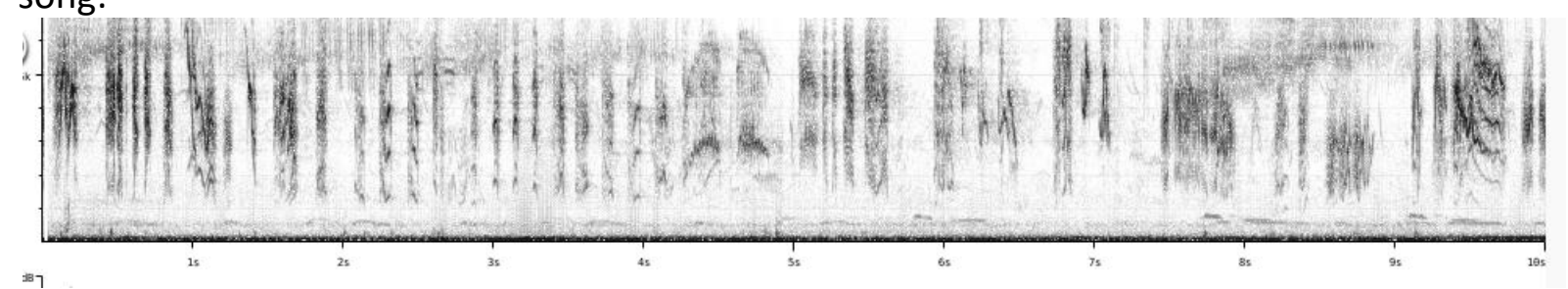

hoarse screechy calls (begging calls)

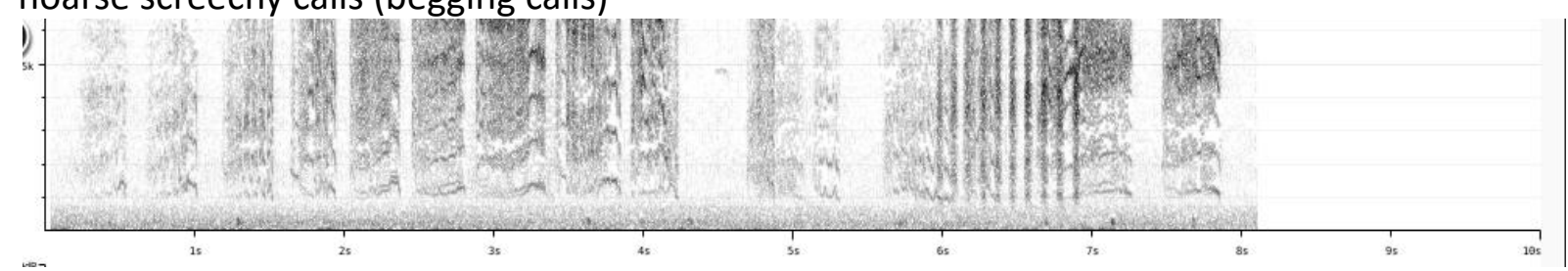



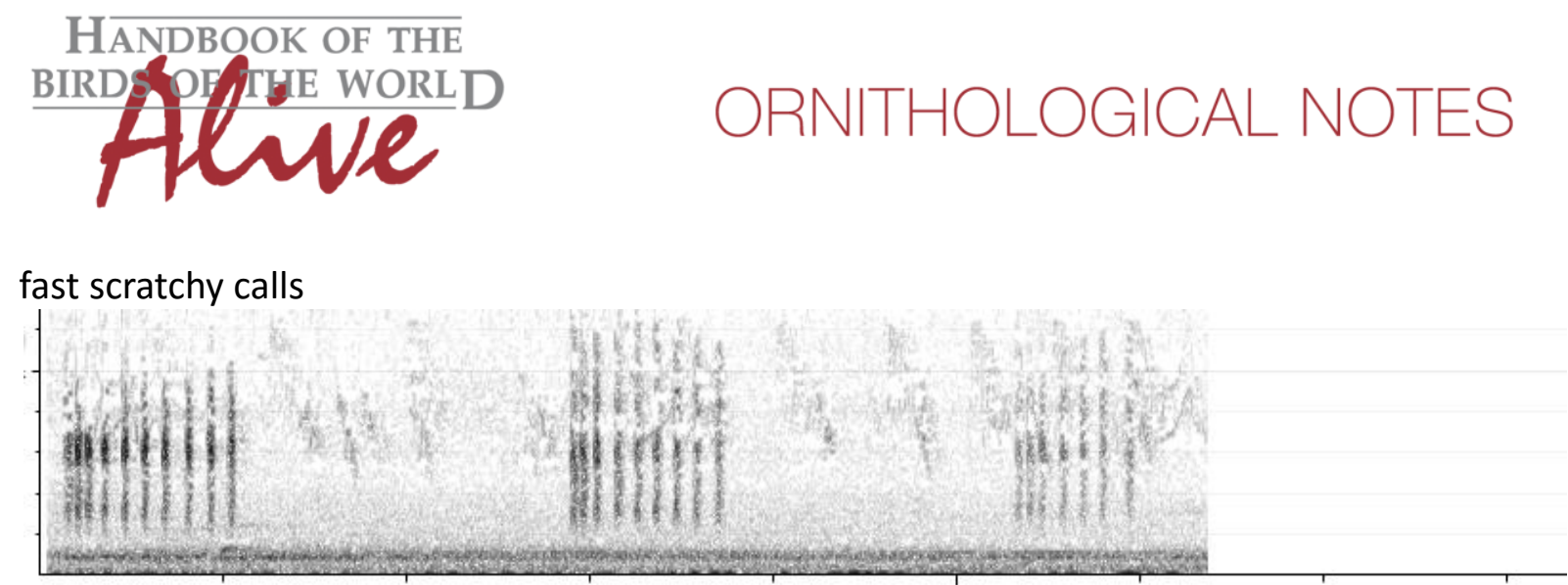

Vocalizations of badius thus seem to fit quite well within the range of vocalizations of other races.

More specifically, song of badius sounds similar to other races, but may differ in having some unique notes. We would need a much larger sample size however to prove this. Variability is high, and probably mimicking is also involved.

For now, we can conclude that there is little indication of significant vocal differences.

This note was finalized on 25th January 2015, using sound recordings available on-line at that moment. We would like to thank in particular the sound recordists who placed their recordings for this species on XC: Patrik Åberg, Bernard Bousquet, Jordi Calvet, Fernand Deroussen, Marco Dragonetti, Jerome Fischer, Terje Kolaas, Tero Linjama, Teus Luijendijk, Igor Maiorano, Mike Nelson, Andrew McCafferty, Cedric Mroczko, Michele Peron, Mathias Ritschard, Jose Carlos Sires Marcin Sotowiej, Nikolay Sariev and Olivier Swift.

\section{References}

Tobias, J.A., Seddon, N., Spottiswoode, C.N., Pilgrim, J.D., Fishpool, L.D.C. \& Collar, N.J. (2010). Quantitative criteria for species delimitation. Ibis 152(4): 724-746.

\section{Recommended citation}

Boesman, P. (2016). Notes on the vocalizations of Woodchat Shrike (Lanius senator). HBW Alive Ornithological Note 202. In: Handbook of the Birds of the World Alive. Lynx Edicions, Barcelona. (retrieved from http://www.hbw.com/node/932149 on 1 September 2016). 